\title{
Impacted lower third molars and distal caries in the mandibular second molar. Is prophylactic removal of lower third molars justified?
}

\author{
José Marques ${ }^{1}$, Marta Montserrat-Bosch ${ }^{2}$, Rui Figueiredo ${ }^{3}$, Miguel-Angel Vilchez-Pérez ${ }^{4}$, Eduard Valmaseda- \\ Castellón ${ }^{5}$, Cosme Gay-Escoda ${ }^{6}$
}

${ }^{1}$ DDS, MS. Master of Oral Surgery and Implantology. Professor of the Oral Surgery and Implantology Master's Degree program. School of Dentistry, University of Barcelona (Spain)

${ }^{2}$ DDS. Master of Oral Surgery and Implantology. School of Dentistry, University of Barcelona. Barcelona (Spain)

${ }^{3}$ DDS, MS, PhD. Master of Oral Surgery and Implantology. Professor of the Oral Surgery and Implantology Master's Degree program. School of Dentistry, University of Barcelona. Researcher of the IDIBELL Institute. Barcelona (Spain)

${ }^{4}$ DDS, MS. Master of Oral Surgery and Implantology. Professor of Oral Surgery. School of Dentistry, University of Barcelona. Professor Coordinator of the Master's in Oral Surgery and Implantology (EFHRE International University / FUCSO). Barcelona (Spain)

${ }^{5} \mathrm{DDS}, \mathrm{MS}, \mathrm{PhD}$. Master of Oral Surgery and Implantology. Director of the Oral Surgery and Implantology Master's Degree program. School of Dentistry, University of Barcelona. Researcher of the IDIBELL Institute. Barcelona (Spain)

${ }^{6} \mathrm{MD}$, DDS, MS, PhD, EBOS, OMFS. Chairman and Full Professor of Oral and Maxillofacial Surgery. School of Dentistry, University of Barcelona. Director of the Master of Oral Surgery and Implantology (EFHRE International University / FUCSO). Coordinator Researcher of the IDIBELL Institute. Head of the Department of Oral and Maxillofacial Surgery, Teknon Medical Center. Barcelona (Spain)

\section{Correspondence:}

Facultat d'Odontologia

Universitat de Barcelona

Campus de Bellvitge

Pavelló de Govern 2 a planta, Despatx 2.9

08907 - L'Hospitalet de Llobregat, Spain

ruipfigueiredo@hotmail.com

\begin{abstract}
Marques J, Montserrat-Bosch M, Figueiredo R, Vilchez-Pérez M, Valmaseda-Castellón E, Gay-Escoda C. Impacted lower third molars and distal caries in the mandibular second molar. Is prophylactic removal of lower third molars justified? J Clin Exp Dent. 2017;9(6):e794-8.

http://www.medicinaoral.com/odo/volumenes/v9i6/jcedv9i6p794.pdf
\end{abstract}

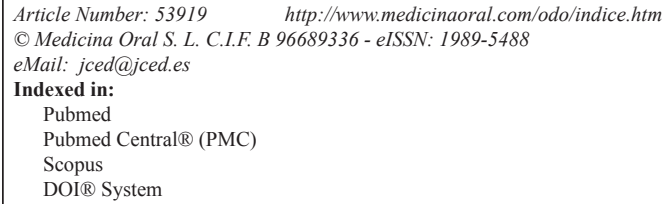

\begin{abstract}
Background: The objective of this study was to evaluate the association between the presence of mandibular third molars and the occurrence of carious lesions in the distal aspect of the mandibular second molar.

Material and Methods: A retrospective cohort study comprising 327 lower third molars extracted in the Oral Surgery and Implantology Master's Degree program of the School of Dentistry of the University of Barcelona (Barcelona, Spain) was carried out. A descriptive and bivariate analysis was made. The diagnosis of caries in the second molar and the position of the mandibular third molar were evaluated through panoramic radiographies.

Results: The sample included 203 patients, 94 males (46.3\%) and 109 females (53.7\%), with a mean age of 26,8 years and 327 lower third molars. The prevalence of second molar distal caries was $25.4 \%(95 \% \mathrm{CI}=20.6 \%$ to $30.2 \%$ ). This pathology was significantly more frequent when the third molar was in a horizontal position (27.7\%),
\end{abstract}


when the contact point was at $(45,8 \%)$ or below $(47.0 \%)$ the cementoenamel junction (CEJ), and when the distal CEJ of the mandibular second molar and the mesial CEJ of the third molar was 7 to $12 \mathrm{~mm}$ apart.

Conclusions: Horizontal lower third molars with contact points at or below the CEJ are more likely to produce distal caries in the mandibular second molars. Due to the high prevalence of this pathology (20.6\% to $30.2 \%$ ), a prophylactic removal of lower third molars with the above-mentioned features might be advisable.

Key words: Second molar, caries, third molar, prophylactic removal.

\section{Introduction}

The removal of impacted lower third molars (L3M) is one of the most frequent procedures in Oral Surgery and several papers have addressed the main indications for these extractions $(1,2)$. The decision to remove L3M associated with a pathology is often straightforward, but the necessity and validity of prophylactic third molar removal has been questioned by many investigators (1-7). Unerupted L3M have been associated with various symptoms and pathologies, such as pericoronitis, pain and swelling, cheek ulcerations, odontogenic cysts, benign or malignant tumors, and systemic infections, among others. These teeth may also affect the adjacent second molars (L2M) producing distal caries, periodontal defects and root resorptions. However, reports have shown that a significant percentage of impacted L3M may remain free of pathology for a long period of time (4,8-10).

Nerve injuries and periodontal complications of the L2M after L3M removal have been widely discussed in the literature $(6,8,9,11,12)$. Nevertheless, few studies relate the position of the $\mathrm{L} 3 \mathrm{M}$ with the prevalence of distal caries in the L2M. According to recently published data, partially impacted third molars with a mesioangular or horizontal inclination that are in close relation with the mandibular second molar cementoenamel junction (CEJ) present a higher risk of causing caries (13-18). This complication often leads to the extraction of both teeth $(19,20)$.

Therefore, it is essential to detect high-risk patients in order to establish a strict follow-up protocol allowing for an early diagnosis of this pathology. Moreover, and depending on the prevalence of this pathology, a debate concerning the prophylactic extraction of selected cases might be necessary $(2-5,10,20)$.

Thus, the aim of the present study is to determine the prevalence of L2M distal caries and to detect the main risk factors, taking into consideration the position of the L3M.

\section{Material and Methods}

A retrospective cohort study comprising 327 lower third molars extracted in the Oral Surgery and Implantology Master's Degree program of the School of Dentistry of the University of Barcelona (Barcelona, Spain) was carried out.
The diagnosis of caries in the $\mathrm{L} 2 \mathrm{M}$ and the position of the L3M were evaluated by a single researcher. All panoramic radiographies had a magnification of 1:1.10 and were assessed under standardized conditions.

The following data were retrieved: gender, age, number of decayed teeth, missing or filled teeth, angulation of the L3M, and distance between the distal surface of the L2M and the mesial surface of the L3M. The distal space and depth of inclusion was determined using the Pell \& Gregory classification as can be observed in figure 1 $(21,22)$. The Leone classification was applied to determine the distance between the distal CEJ of the L2M and mesial CEJ of the adjacent mandibular third molar (1-3 mm, 4-6 mm, 7-9 mm, 10-12 mm, or $\geq 13 \mathrm{~mm}$ ) (Fig. 2) (23).

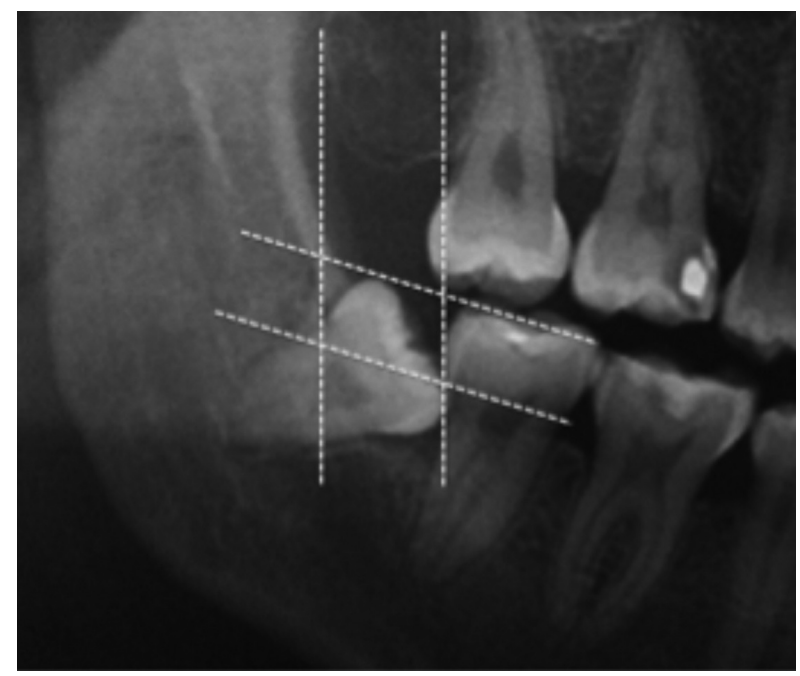

Fig. 1: The distal space and depth of inclusion was determined by the Pell \& Gregory classification method.

The angulation of the L3M was calculated by measuring the angle formed by the mandibular occlusal plane and the occlusal surface of the third molar, as described by Schiller (vertical $0^{\circ}-10^{\circ}$, mesioangular or distoangular $11-70^{\circ}$ and horizontal $\geq 71^{\circ}$ ) (24). Radiolucent pericoronal images of more than $2.5 \mathrm{~mm}$ were considered pathological (4). 


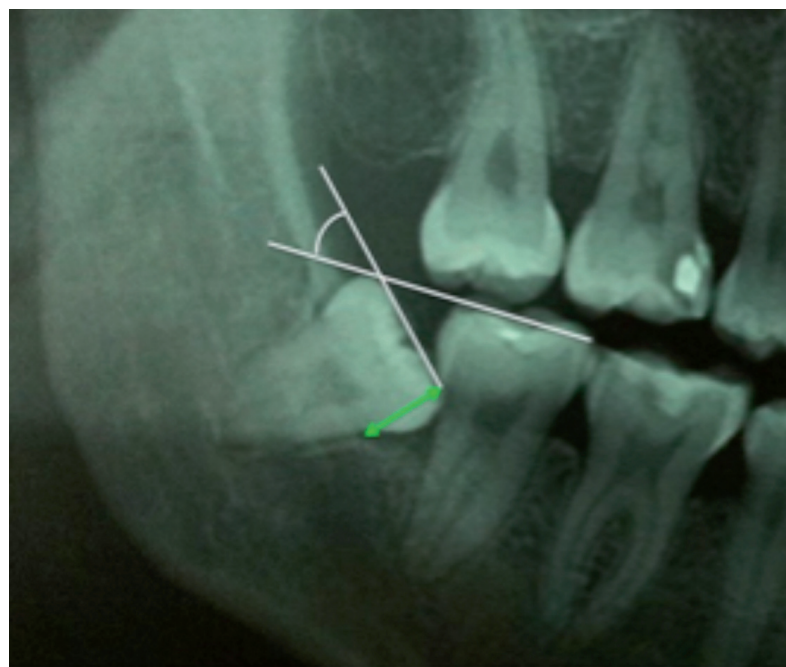

Fig. 2: The Leone classification was applied to determine the distance between the distal CEJ of the L2M and mesial CEJ of the L3M (1-3 mm, 4-6 mm, 7-9 mm, 10-12 mm, or $\geq 13 \mathrm{~mm}$ ). The angulation of the L3M was calculated by measuring the angle formed by the mandibular occlusal plane and the occlusal surface of the third molar, as described by Schiller (vertical $0^{\circ}-10^{\circ}$, mesioangular or distoangular $11-70^{\circ}$ and horizontal $\geq 71^{\circ}$ ). CEJ: cementoenamel junction; L3M: lower third molar; L2M: lower second molar.

In order to avoid interexaminer bias, a single investigator carried out the measurements. To test intra-examiner agreement, 10 patients were assessed twice and the intra-class correlation coefficient (ICC) was calculated $(0,98)$.

The data obtained was analyzed using SPSS 19.0 statistical package (SPSS Inc., Chicago, IL, USA). When the distribution was compatible with normality, the mean and standard deviation (SD) were used. A bivariate analysis using Pearson's chi-square and student t-tests was made. The level of significance was set at $p<0.05$ and a $95 \%$ confidence interval $(95 \% \mathrm{CI})$ was calculated for the prevalence.

\section{Results}

Two hundred and three patients with 327 impacted L3M were included in the study. A total of 94 males (46.3\%) and 109 females $(53.7 \%)$ with a mean age of 26.8 years ( $\mathrm{SD}=7$; range 18-45) were analyzed.

The prevalence of L2M distal caries was $25.4 \%(95 \% \mathrm{CI}=$ $20.6 \%$ to $30.2 \%$ ). When the L3M was horizontal, the prevalence of caries increased significantly $(27.7 \% \mathrm{Vs}$. $13.9 \%)(\mathrm{x} 2=14.48 ; \mathrm{df}=3 ; p=0.001)$. Considering the contact point, when it was at or below the CEJ, a higher number of L2M caries was observed (45.8\% and $47.0 \%$ respectively versus $7.2 \%$ when the contact point was above the CEJ) $(\mathrm{x} 2=27,65 ; \mathrm{df}=2 ; p=0.001)$. This complication also increased significantly when the distal CEJ of the L2M and mesial CEJ of the adjacent L3M were 7-9 $\mathrm{mm}$ and $10-12 \mathrm{~mm}$ apart (36.7\% and 36.6\%, respectively; $\mathrm{x} 2=18.54 ; \mathrm{df}=4 ; p=0.002$ ) (Table 1 ).
Age did not seem to be significantly related with development of distal caries on the L2M due to the impaction of L3M ( $\mathrm{t}=0.152 ; p=0.697)$.

\section{Discussion}

Previous studies pointed out that second molars with adjacent impacted L3M have a prevalence of caries ranging from 7 to $32 \%(6,9,14,15,25)$. Authors such as Kang et al. (17) reported even higher figures (52\%), probably due to the use of cone-beam computed tomography (CBCT) to diagnose caries. According to the present study, the prevalence of L2M distal caries ranges from 20.6 - 30.2\%, confirming the findings reported by Özeç et al. (14), in a Turkish population (20\%), and van der Linden et al. (32\%) (26). It must be pointed out that all patients of our sample were initially evaluated by a general dental practitioner that recommended L3M extraction. Thus, it is likely that the prevalence of complications associated with the L3M in the present sample is higher than in the general population.

McArdle and Renton (27) concluded that L3M position is a more relevant factor for L2M distal caries development in comparison with other variables such as high susceptibility to dental caries in general. Regarding the angulation of the impacted tooth, most authors state that a mesioangular tilt seems to be highly associated with caries occurrence, while vertical, distoangular or ectopic impactions are unlikely to originate this pathology $(6,8,13-15,17-19,25)$. However, the present study shows that a horizontal angulation might also be an important risk factor.

The influence of the contact point location between the second and third molars on the formation of second molar distal caries has been well documented in the literature, with similar findings to the ones of our sample $(14,17)$. In our opinion, contact points below the CEJ are more difficult to clean, leading to higher plaque accumulation. On the other hand, third molars are associated with certain bacteria and inflammatory mediators that might enhance the development of periodontitis and caries on the adjacent teeth $(13,18)$.

It has been suggested that the initiation and severity of distal caries in second molars increases over time, and that older patients have higher incidences of this complication $(17,25)$. Nevertheless, the results of the present study did not show any relation between these 2 factors, probably due to the low mean age of the sample.

One of the main limitations of this study was the use of panoramic radiographies, since these have been shown to be inferior to intraoral techniques in detecting interproximal caries. Therefore, early carious lesions may not have been detected, which might have led to an underestimation in the diagnosis of L2M caries.

The development of caries in the distal aspect of the mandibular second molar not only indicates the need for 
Table 1: Relationship between second molar distal caries, third molar angulation, contact point, CEJ distance, distal space and impaction depth. L3M: Lower third molar. CEJ: cementoenamel junction. L2M: Lower second molar.

\begin{tabular}{|c|c|c|c|c|c|}
\hline & \multicolumn{2}{|c|}{ Distal caries in L2M } & \multirow{2}{*}{ Total } & \multirow{2}{*}{ Bivariate $(p)$} \\
\hline & & No & Yes & & \\
\hline \multirow{4}{*}{ L3M Angulation } & Distoangular & $30(12.3 \%)$ & $15(18.1 \%)$ & $45(13.8 \%)$ & \multirow{5}{*}{0.001} \\
\hline & Horizontal & $34(13.9 \%)$ & $23(27.7 \%)$ & $57(17.4 \%)$ & \\
\hline & Mesioangular & $97(39.8 \%)$ & $31(37.3 \%)$ & $128(39.1 \%)$ & \\
\hline & Vertical & $83(34.0 \%)$ & $14(16.9 \%)$ & $97(29.7 \%)$ & \\
\hline \multicolumn{2}{|c|}{ Total } & $244(100.0 \%)$ & $83(100.0 \%)$ & $327(100.0 \%)$ & \\
\hline \multirow{3}{*}{ Contact Point } & Above CEJ & $87(35.7 \%)$ & $6(7.2 \%)$ & $93(28.4 \%)$ & \multirow{4}{*}{0.001} \\
\hline & Below CEJ & $62(25.4 \%)$ & $39(47.0 \%)$ & $101(30.9 \%)$ & \\
\hline & CEJ & $95(38.9 \%)$ & $38(45.8 \%)$ & $133(40.7 \%)$ & \\
\hline \multicolumn{2}{|c|}{ Total } & $244(100.0 \%)$ & $83(100.0 \%)$ & $327(100.0 \%)$ & \\
\hline \multirow{5}{*}{ CEJ distance } & $1-3 \mathrm{~mm}$ & $98(40.2 \%)$ & $16(19.3 \%)$ & $114(34.9 \%)$ & \multirow{6}{*}{0.002} \\
\hline & $4-6 \mathrm{~mm}$ & $38(15.6 \%)$ & $11(13.3 \%)$ & $49(15.0 \%)$ & \\
\hline & $7-9 \mathrm{~mm}$ & $72(29.5 \%)$ & $40(48.2 \%)$ & $112(34.3 \%)$ & \\
\hline & $10-12 \mathrm{~mm}$ & $26(10.7 \%)$ & $15(18.1 \%)$ & $41(12.5 \%)$ & \\
\hline & $>13 \mathrm{~mm}$ & $10(4.1 \%)$ & $1(1.2 \%)$ & $11(3.4 \%)$ & \\
\hline \multicolumn{2}{|c|}{ Total } & $244(100.0 \%)$ & $83(100.0 \%)$ & $327(100.0 \%)$ & \\
\hline \multirow{3}{*}{ Distal space } & $\mathrm{I}$ & $77(31.6 \%)$ & $21(25.3 \%)$ & $98(30.0 \%)$ & \multirow{4}{*}{0.495} \\
\hline & II & $156(63.9 \%)$ & $59(71.2 \%)$ & $215(65.7 \%)$ & \\
\hline & III & $11(4.5 \%)$ & $3(3.6 \%)$ & $14(4.3 \%)$ & \\
\hline \multicolumn{2}{|c|}{ Total } & $244(74.6 \%)$ & $83(25.4 \%)$ & $327(100.0 \%)$ & \\
\hline \multirow{3}{*}{$\begin{array}{l}\text { Impaction } \\
\text { depth }\end{array}$} & $\mathrm{A}$ & $57(23.4 \%)$ & $22(26,5 \%)$ & $79(24.2 \%)$ & \multirow{4}{*}{0.493} \\
\hline & $\mathrm{B}$ & $158(64.8 \%)$ & $48(57.8 \%)$ & $206(63.0 \%)$ & \\
\hline & $\mathrm{C}$ & $29(11.9 \%)$ & $13(15.7 \%)$ & $42(12.8 \%)$ & \\
\hline \multicolumn{2}{|c|}{ Total } & $244(100.0 \%)$ & $83(100.0 \%)$ & $327(100.0 \%)$ & \\
\hline
\end{tabular}

L3M extraction, but also requires restorative and possible endodontic treatments of the adjacent second molar. Furthermore, L2M extraction might be necessary in cases where the carious lesion is subgingival (19). Therefore, the identification of high-risk cases is crucial and, in our opinion, the prophylactic removal of these teeth is recommended.

Horizontal or mesioangular lower third molars with contact points at or below the CEJ are more likely to produce distal caries in the mandibular second molars. Due to the high prevalence of this pathology (20.6\% to $30.2 \%$ ), a prophylactic removal of lower third molars with the above-mentioned features might be advisable.

\section{References}

1. Coulthard P, Bailey E, Esposito M, Furness S, Renton TF, Worthington $\mathrm{H} \mathrm{V}$. Surgical techniques for the removal of mandibular wisdom teeth. Cochrane Database Syst Rev. 2014;7:CD004345.

2. McArdle LW, Renton T. The effects of NICE guidelines on the management of third molar teeth. Br Dent J. 2012;213:1-7.

3. Ghaeminia H, Perry J, Nienhuijs MEL, Toedtling V, Tummers M, Hoppenreijs TJ, et al. Surgical removal versus retention for the management of asymptomatic disease-free impacted wisdom teeth. Cochrane Database Syst Rev. 2016;8:CD00003879.

4. Ventä I, Ylipaavalniemi P, Turtola L. Long-term evaluation of estimates of need for third molar removal. J Oral Maxillofac Surg. 2000;58:288-91.

5. Rafetto LK. Removal of asymptomatic third molars: A supporting view. J Oral Maxillofac Surg. 2006;64:1811-5.

6. Polat HB, Ozan F, Kara I, Ozdemir H, Ay S. Prevalence of commonly found pathoses associated with mandibular impacted third molars based on panoramic radiographs in Turkish population. Oral Surg Oral Med Oral Pathol Oral Radiol Endod. 2008;105:41-7.
7. Mettes TDG, Ghaeminia H, Nienhuijs MEL, Perry J, van der Sanden WJM, Plasschaert A. Surgical removal versus retention for the management of asymptomatic impacted wisdom teeth. Cochrane database Syst Rev. 2012;6:CD003879.

8. Akarslan ZZ, Kocabay C. Assessment of the associated symptoms, pathologies, positions and angulations of bilateral occurring mandibular third molars: Is there any similarity? Oral Surg Oral Med Oral Pathol Oral Radiol Endod. 2009;108:e26-32.

9. Al-Khateeb TH, Bataineh AB. Pathology Associated with impacted mandibular third molars in a group of Jordanians. J Oral Maxillofac Surg. 2006;64:1598-602.

10. Bouloux GF, Busaidy KF, Beirne OR, Chuang SK, Dodson TB. What is the risk of future extraction of asymptomatic third molars? A systematic review. J Oral Maxillofac Surg. 2015;73:806-11.

11. Sigron G, Pourmand P, Mache B, Stadlinger B, Locher M. The most common complications after wisdom-tooth removal. Swiss Dent J. 2014;124:1052-6.

12. Pogrel MA. What is the effect of timing of removal on the incidence and severity of complications? J Oral Maxillofac Surg. 2012;70:3740.

13. McArdle LW, Patel N, Jones J, McDonald F. The mesially impacted mandibular third molar: The incidence and consequences of distal cervical caries in the mandibular second molar. Surgeon. 2016;5:1-7. 14. Ozeç I, Herguner Siso S, Tasdemir U, Ezirganli S, Goktolga G. Prevalence and factors affecting the formation of second molar distal caries in a Turkish population. Int J Oral Maxillofac Surg. 2009;38:1279-82.

15. Chang SW, Shin SY, Kum KY, Hong J. Correlation study between distal caries in the mandibular second molar and the eruption status of the mandibular third molar in the Korean population. Oral Surg Oral Med Oral Pathol Oral Radiol Endod. 2009;108:838-43.

16. de Lange J. Third molars and second molar distal caries. Int J Oral Maxillofac Surg. 2010;39:630-2.

17. Kang F, Huang C, Sah MK, Jiang B. Effect of eruption status of the mandibular third molar on distal caries in the adjacent second molar. $\mathrm{J}$ Oral Maxillofac Surg. 2016;74:684-92. 
18. Nunn ME, Fish MD, Garcia RI, Kaye EK, Figueroa R, Gohel A, et al. Retained asymptomatic third molars and risk for second molar pathology. J Dent Res. 2013;92:1095-9.

19. Oenning AC, Melo SL, Groppo FC, Haiter-Neto F. Mesial inclination of impacted third molars and its propensity to stimulate external root resorption in second molars: A cone beam computed tomography evaluation. J Oral Maxillofac Surg. 2015;73:279-86.

20. Yadav P, Pruthi PJ, Nawal RR, Talwar S, Verma M. Saving the 2nd molar from the 3rd Is it really the guilt of the tilt? J Clin Diagnostic Res. 2016;10:ZC17-9.

21. Pell GJ, Gregory BT. Impacted mandibular third molars: Classification and modified techniques for removal. Dent Dig. 1933;39:330-8.

22. Almendros-Marqués N, Berini-Aytés L, Gay-Escoda C. Evaluation of intraexaminer and interexaminer agreement on classifying lower third molars according to the systems of Pell and Gregory and of Winter. J Oral Maxillofac Surg. 2008;66:893-9.

23. Leone SA, Edenfield MJ, Cohen ME. Correlation of acute pericoronaritis and the position of the mandibular third molar. Oral Surg Oral Med Oral Pathol. 1986;62:245-50.

24. Shiller WR. Positional changes in mesio-angular impacted mandibular third molars during a year. J Am Dent Assoc. 1979;99:460-4.

25. Falci SGM, de Castro CR, Santos C, de Souza Lima LD, RamosJorge ML, Botelho AM, et al. Association between the presence of a partially erupted mandibular third molar and the existence of caries in the distal of the second molars. Int J Oral Maxillofac Surg. 2012;41:1270-4.

26. Van der Linden W, Cleaton-Jones P, Lownie M. Diseases and lesions associated with third molars. Review of 1001 cases. Oral Surg Oral Med Oral Pathol Oral Radiol Endod. 1995;79:142-5.

27. McArdle LW, Renton TF. Distal cervical caries in the mandibular second molar: An indication for the prophylactic removal of the third molar? Br J Oral Maxillofac Surg. 2006;44:42-5.

Acknowledgements

This study was supported by the consolidated research group "Dental and Maxillofacial Therapeutics and Pathology" of Biomedical Research Institute of Bellvitge (IDIBELL) with the financial support of teaching-care agreement of Oral Surgery from the University of Barcelona, the Consorci Sanitari Integral and the Servei Català de la Salut de la Generalitat de Cataluya (Catalan Health Service).

\section{Conflict of interest}

The authors declare that there are no conflicts of interest in this study. 